\title{
A Pragmatic Approach to Full Mouth Rehabilitation
}

\section{${ }^{1}$ Amit Krishnarao Jagtap, ${ }^{2}$ Pradeep Dinkar Chaudhari, ${ }^{3}$ Jitendra Anil Bhandari}

\begin{abstract}
Restoring the edentulous patient with an esthetic and functional restoration may present numerous challenges to the clinician. The patient's occlusal vertical dimension, centric relation, esthetics and phonetics need to be determined and maintained throughout the restorative process. This clinical report describes the fabrication of implant supported fixed prosthesis in the mandibular posterior region, a tooth supported fixed prosthesis in the mandibular anterior region and a tooth supported maxillary overdenture with a low profile attachment. A step by step approach to provide an esthetic result is described.
\end{abstract}

Keywords: Low profile attachments, Full mouth rehabilitation, Prosthesis, Overdenture.

How to cite this article: Jagtap AK, Chaudhari PD, Bhandari JA. A Pragmatic Approach to Full Mouth Rehabilitation. Int J Prosthodont Restor Dent 2014;4(1):14-19.

Source of support: Nil

Conflict of interest: None declared

\section{INTRODUCTION}

Loss of natural teeth results in both esthetic and functional deficits as the age of the patient advances. This leads to a significant reduction in the patient's quality of life and selfimage perception. Therefore, offering the correct treatment options to the patients losing their teeth either due to extraction or as a natural physiologic process is an important aspect of comprehensive patient treatment. In today's dental practice, many published papers suggest the application of implants in management of partially edentulous patients which serve as an abutment for either crowns or fixed partial denture. ${ }^{1,2}$ There are numerous studies using combination of implants and removable prosthesis. ${ }^{3}$ However, a combination of implants and fixed prosthesis was found to be difficult to implement. ${ }^{4,5}$ These contraindications can be based on either the patient's medical condition or

\footnotetext{
${ }^{1,2}$ Professor, ${ }^{3}$ Postgraduate Student

1,3 Department of Prosthodontics, Dr DY Patil Dental College Navi Mumbai, Maharashtra, India

${ }^{2}$ Department of Conservative Dentistry and Endodontics Bharati Vidyapeeth Dental College and Hospital, Navi Mumbai Maharashtra, India

Corresponding Author: Amit Krishnarao Jagtap, Professor Department of Prosthodontics, Dr DY Patil Dental College Navi Mumbai, Maharashtra, India, Phone: 9370467795 , e-mail: amitjagtap13@gmail.com
}

surgical concerns, such as close proximity of the sinus floor or mandibular nerve. In view of all these considerations, a pragmatic approach to full mouth rehabilitation of a geriatric patient using a combination of implant-supported prosthesis, tooth-supported prosthesis and a tooth-supported attachment retained overdenture was planned in this present case report.

\section{CASE REPORT}

A 65 years old male patient reported to the department of prosthodontics with a desire to get his missing teeth replaced with a fixed prosthesis. The patient previously was using a removable prosthesis with which he had difficulty to adjust and, hence, was looking for a fixed prosthetic option.

After initial consultation, a complete extraoral and intraoral examination of the patient was done. Appointment was scheduled for a complete medical examination, panoramic radiograph and cone beam computed tomography (CBCT). The patient presented with a collapsed extraoral profile (Fig. 1). Intraoral examination revealed presence of partially edentulous maxillary and mandibular arches. The maxillary arch had two canines and a first premolar in the first quadrant which had been endodontically treated with their coronal portion sectioned to gingival level (Fig. 2). The mandibular arch revealed the bilateral canines and second premolars of both quadrants which were also endodontically treated.

A complete medical and hematological examination revealed no absolute contraindication to any therapeutic or surgical modality. Cone beam computed tomography revealed close proximity of sinus floor to a maxillary posterior alveolar ridge and inadequate buccolingual bone dimensions in mandibular anterior region (Fig. 3). A complete intraoral analysis was done, and the following treatment modality was decided:

1. An interim fixed partial denture with porcelain fused to metal prosthesis to replace mandibular anteriors.

2. Implant-supported fixed prosthesis in both posterior quadrants of the mandibular arch.

3. A tooth supported maxillary overdenture with a low profile attachment system.

Due to financial constraints, the patient opted for bone augmentation and implant placement in the mandibular anterior and maxillary region at a later date.

\section{TREATMENT PROCEDURE}

As a first step of treatment in consideration of the periodontal condition of the teeth, a subgingival scaling was performed 

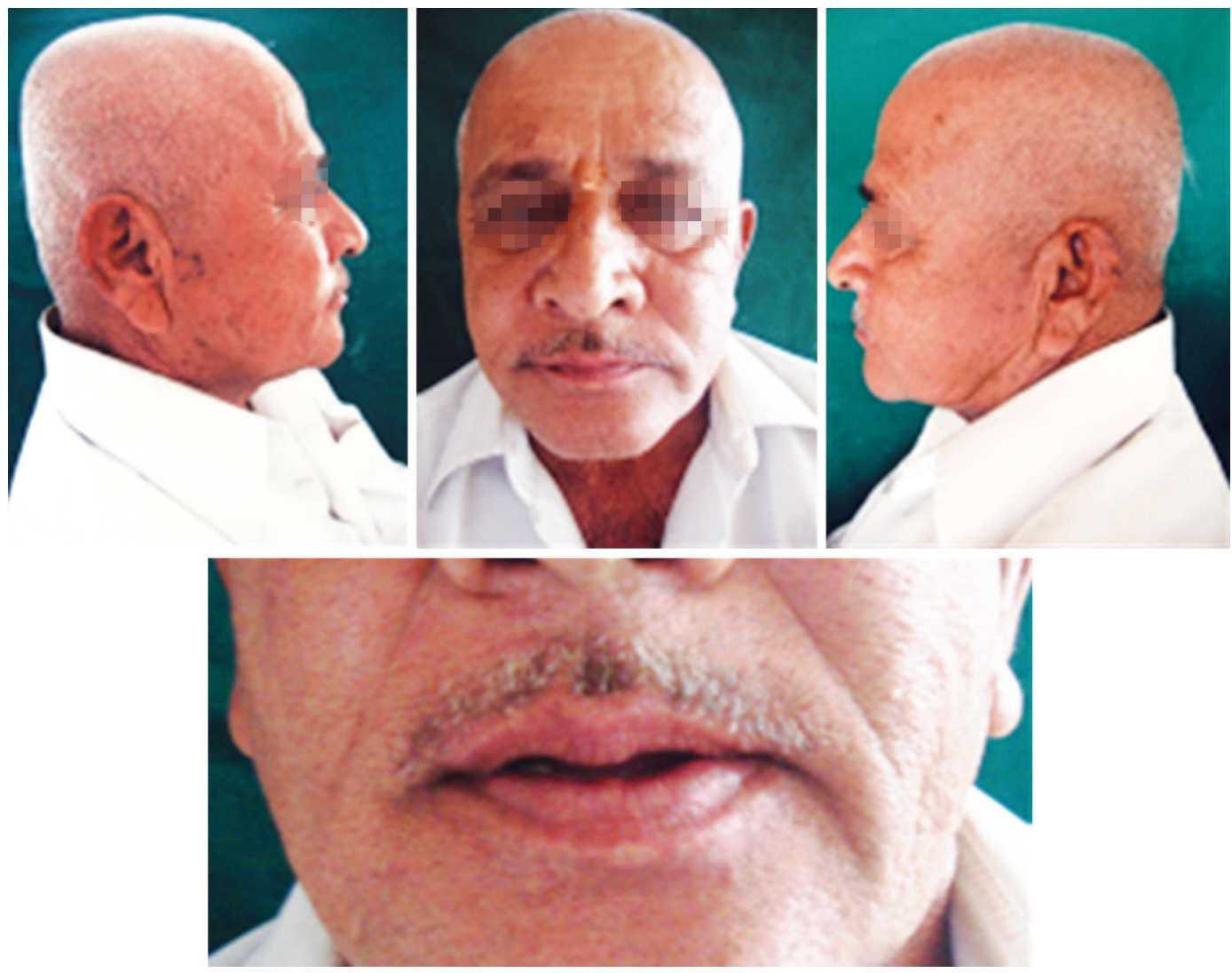

Fig. 1: Preoperative extraoral views
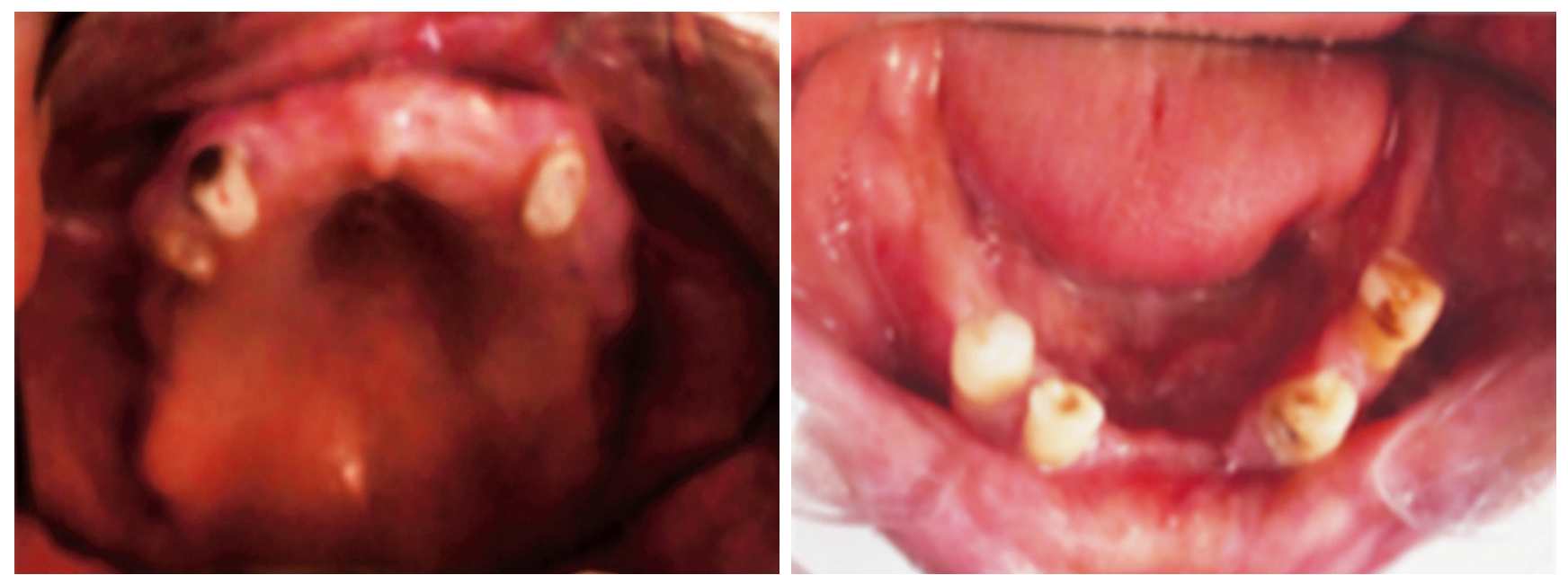

Fig. 2: Preoperative intraoral views

and re-evaluated after a period of 1 week. The treatment plan was divided into two phases: a surgical phase and a prosthetic phase.

Surgical phase involved placement of implants in 46, 47 and 36, 37 region. The radiographic stent was modified and converted to a surgical stent. Vital signs were checked and consent sign had been obtained from the patient prior to the surgery. Patient was advised prophylactic antibiotics, i.e. amoxicillin, 1 hour prior to the surgery. After administering local anesthesia, a crestal incision was performed with a number 15 bard parker blade and a full thickness mucoperiosteal flap was raised. Osteotomies were performed in the $46(4.6 \mathrm{~mm}$ by $12 \mathrm{~mm}), 47(3.8 \mathrm{~mm}$ by $10.5 \mathrm{~mm})$ and $36(3.8 \mathrm{~mm}$ by $9 \mathrm{~mm}), 37(4.6 \mathrm{~mm}$ by $10.5 \mathrm{~mm})$. Endosseous implants were placed in the planned position and the flap was sutured with 4-0 silk sutures (Fig. 4). Patient was prescribed antibiotics and analgesics for a period of 5 days.

During the healing phase, appointments were scheduled for the prosthetic phase, i.e. fixed partial denture prepara-tion in the mandibular anterior region (Fig. 5). Teeth nos 43, 45 and 33, 35 were prepared. Even though the bone support for these abutments was moderate they were used, since they were going to support an interim partial denture. Elastomeric impressions were made and temporization done (Fig. 6). 


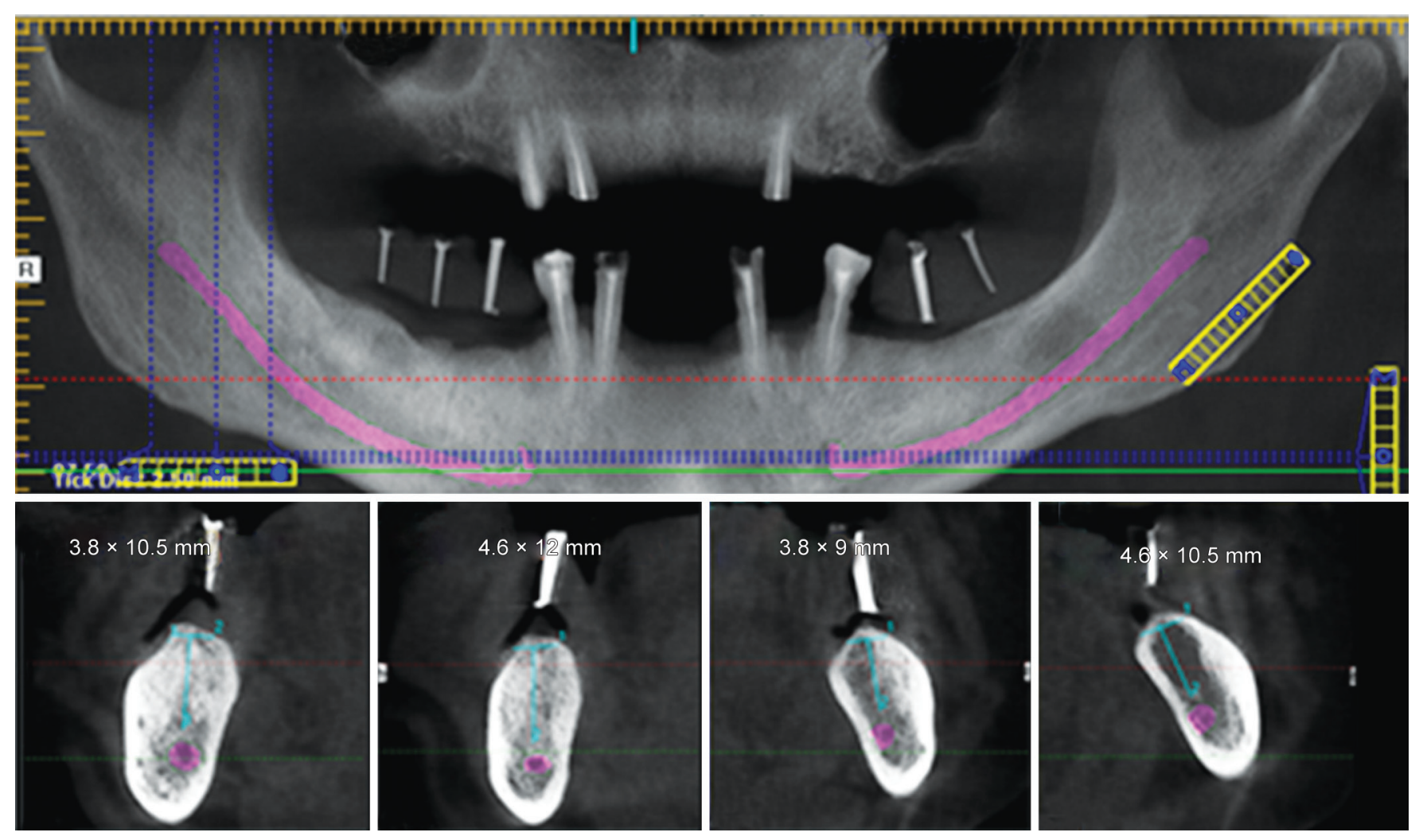

Fig. 3: Cone beam computed tomography
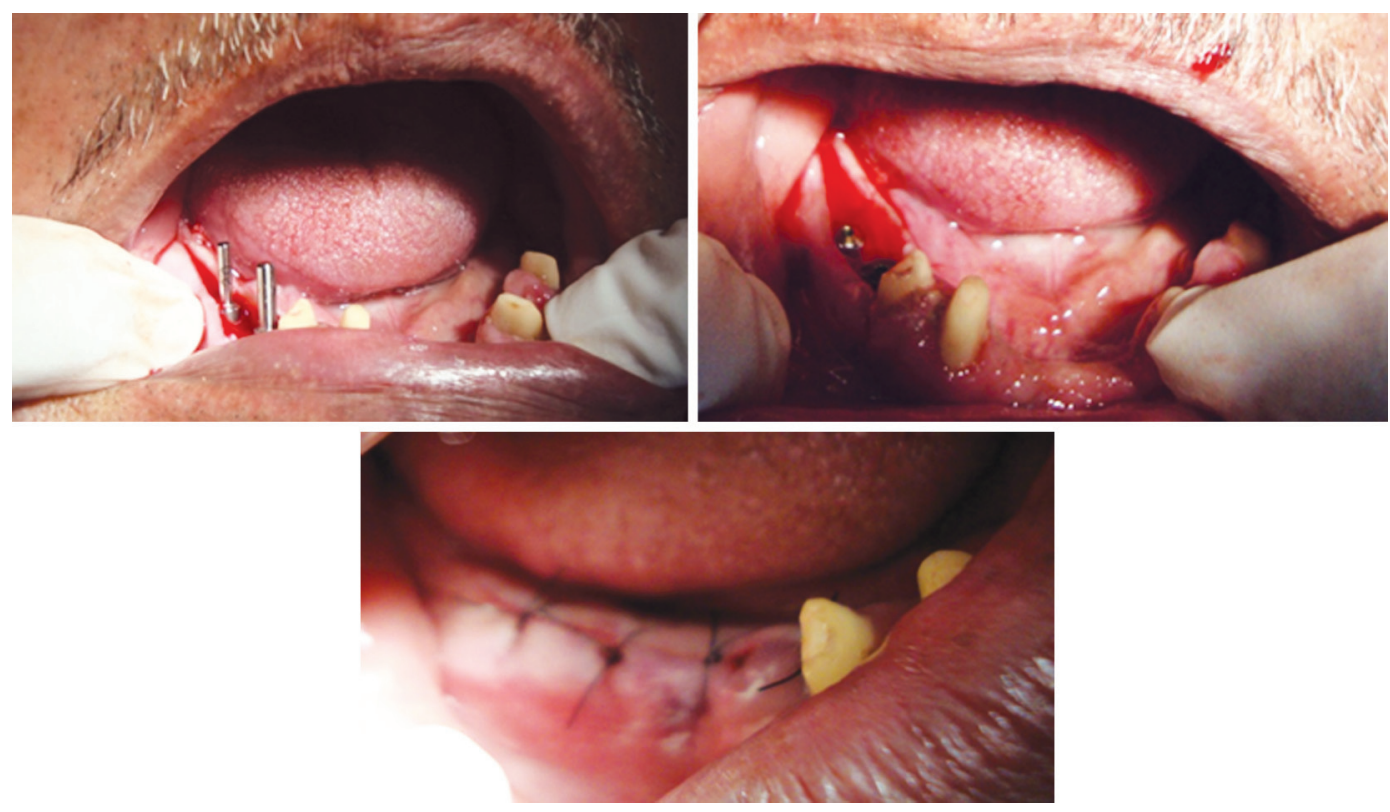

Fig. 4: Implant placement fourth quadrant

Maxillary denture was fabricated till the try-in stage. Esthetics was analyzed in the patients mouth, and the mandibular temporary restorations were modified accordingly. Mandibular porcelain fused to metal fixed partial denture was subsequently fabricated and cemented (Fig. 7). Maxillary denture was also processed simultaneously.

After a period of 4 months, stage 2 surgery to uncover the mandibular bilateral posterior implants was done. Gingival formers were placed for 1 week and then closed tray impression was made (Fig. 8). Porcelain fused to metal crowns were fabricated and cemented with zinc phosphate cement (Fig. 9).

Low profile attachments (Access post, Essential dental systems, NJ, USA) were cemented in teeth nos 13 and 23. The Nylon housings were picked up in cold cure acrylic resin in the maxillary denture (Fig. 10).

Recall appointments were given for cleaning and maintenance of the prosthesis at every 3 months interval during the first year and every 6 months later. 


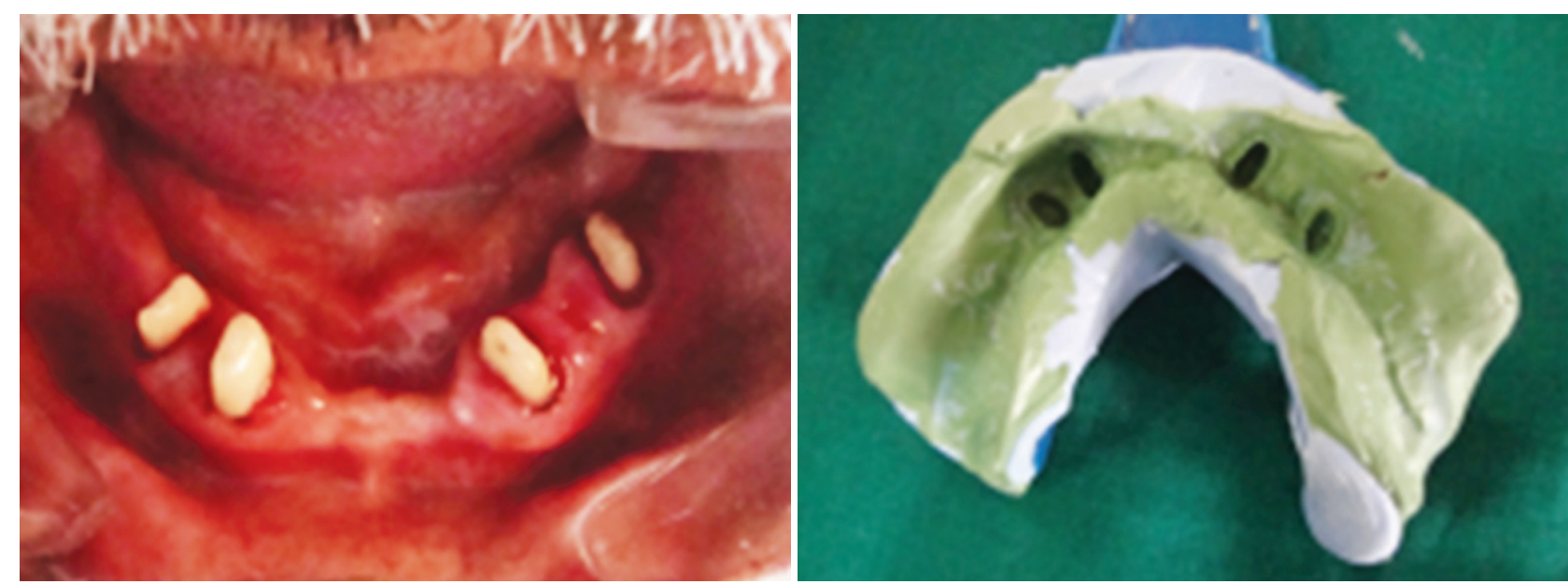

Fig. 5: Mandibular teeth preparation and final impression
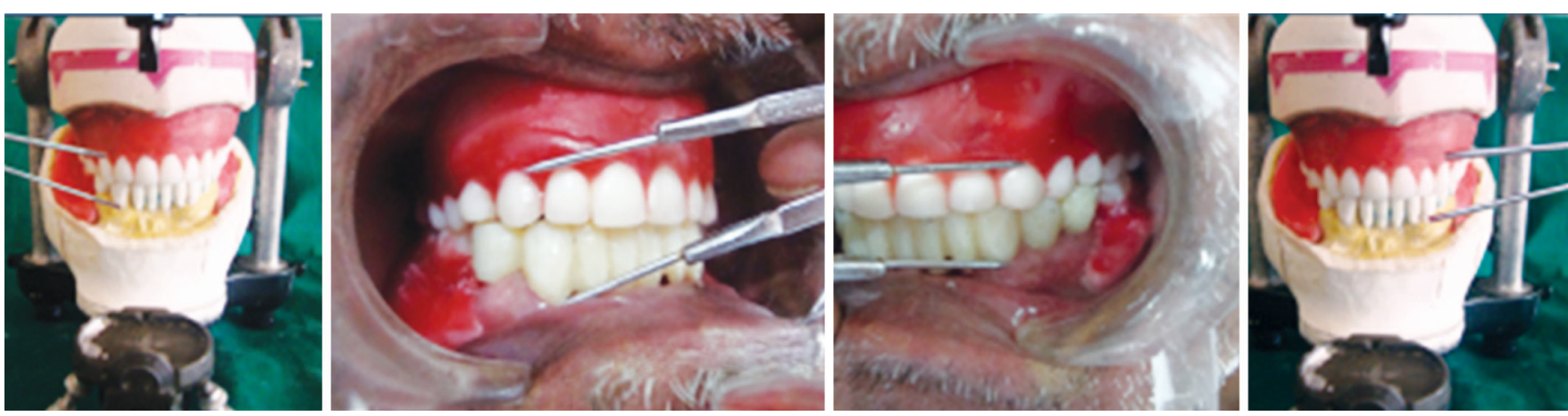

Fig. 6: Temporization and re-evaluation of centric and vertical jaw relations

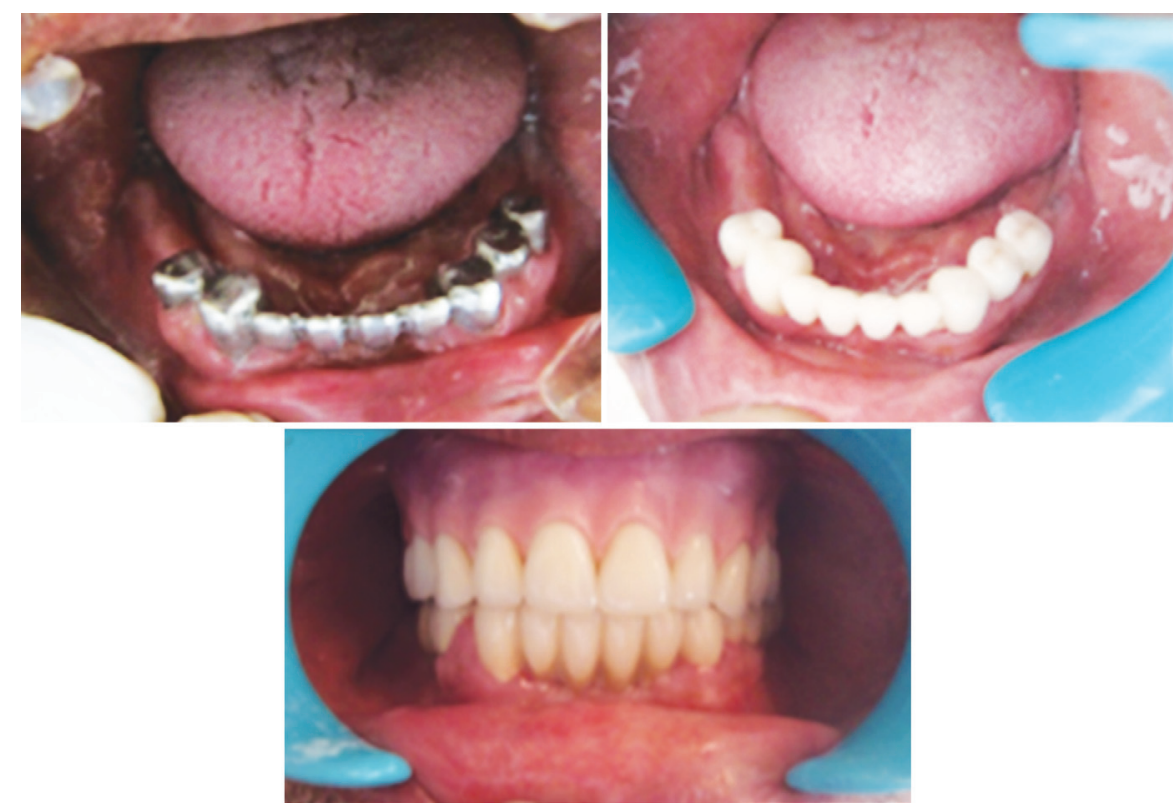

Fig. 7: Coping trial, bisque trial, final prosthesis and maxillary acrylized denture

\section{DISCUSSION}

In the current treatment procedure, extensive restorations were required to optimize the patient's occlusion. Therefore, a reorganized approach is needed as the present intercuspal position (ICP) is unacceptable and needs to be changed. The ICP is developed at the centric relation position of the mandible. This provides an even and stable occlusion and also ensures there were no pathological deflective contacts. Therefore, most of all full mouth rehabilitations tread this approach as it restores the structural and functional integrity of the dental arches that are compromised due to multiple missing teeth.

Rehabilitation of patients with missing bilateral posterior teeth and moderate to severe bone loss, presents one of the most complex treatment modalities due to shift in sinus floor position, 


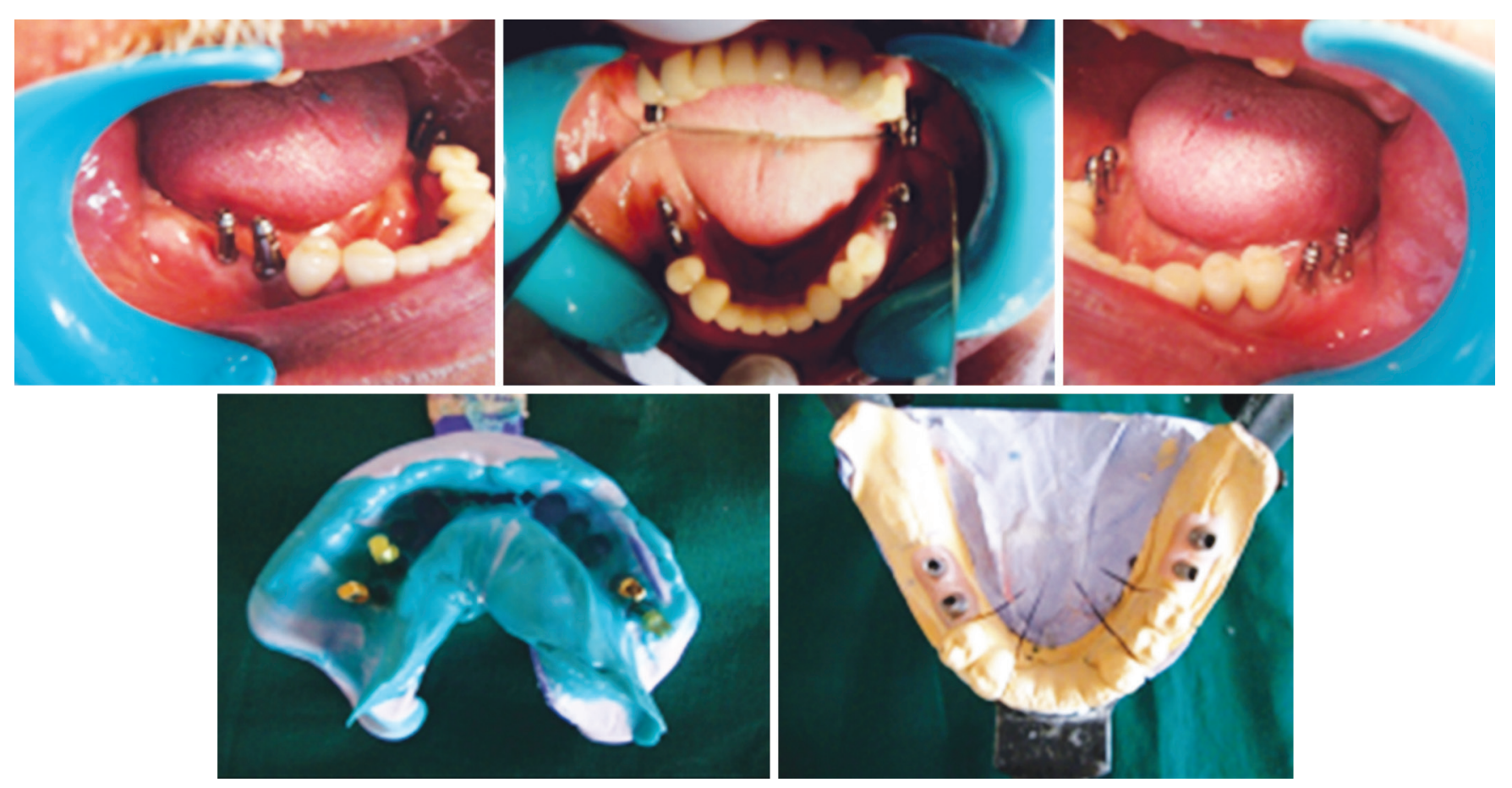

Fig. 8: Closed tray impression
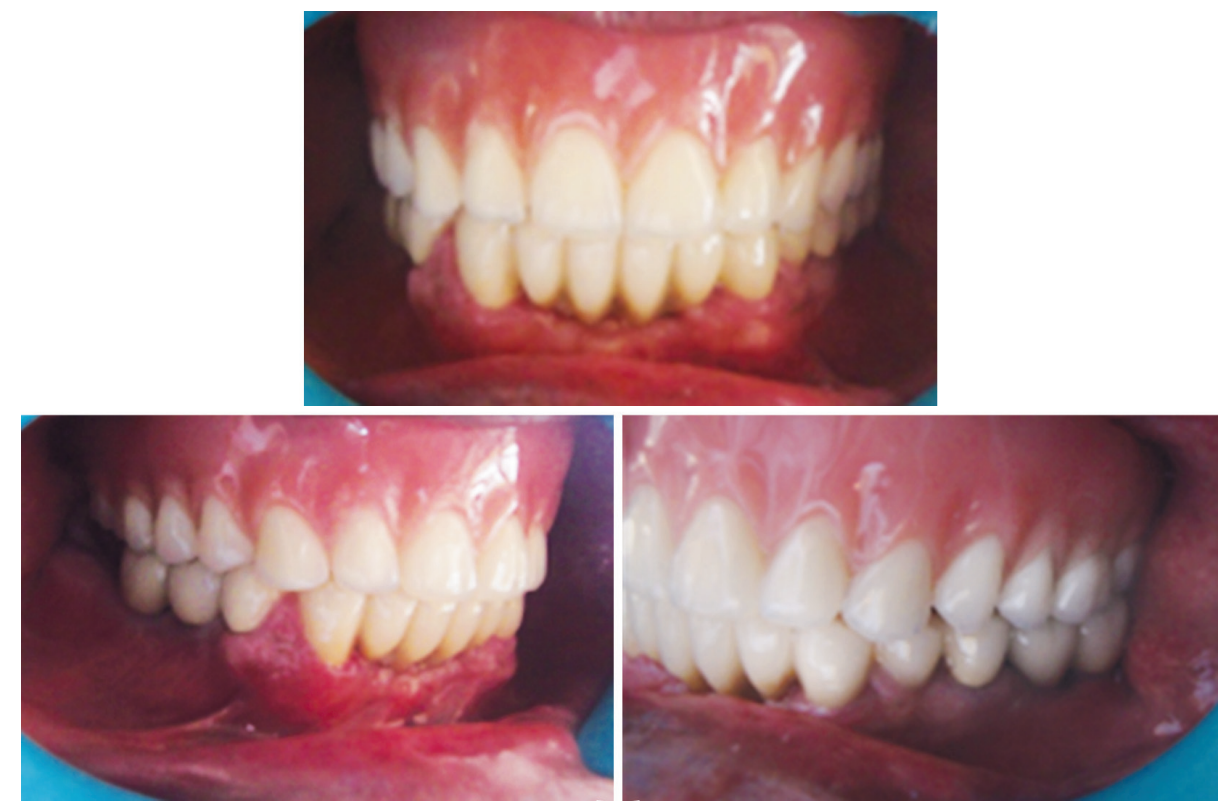

Fig. 9: Completed rehabilitation

hindering the replacement with fixed prosthesis, i.e. implants. Sinus floor augmentation with wide range of biomaterials and bone replacement grafts using various techniques presents a challenging treatment option in such conditions. ${ }^{6-8}$ However, in this case, the patients financial constraints eliminated the fixed treatment option in the maxillary arch. Therefore, an overdenture was planned as an alternate treatment option.

According to Dawson, anterior teeth play a dominant role in establishing the functional path the mandible can travel. Therefore, the position and contour of lower anterior teeth should be the starting point of occlusal design as they are the beginning of functional movements that establish the anterior guidance and the envelope of motion. ${ }^{9}$ Taking this into consideration, a segmental or quadrant-wise rehabilitation has been followed.

\section{CONCLUSION}

Creating the perfect smile along with health is a challenging procedure that requires meticulous understanding of the patients' needs and treatment planning.

The integration of different replacement procedures in complex full mouth rehabilitations requiring multiple restorations, especially in a geriatric patient can be a challenging task for a dental clinician. In the present case report, the use 

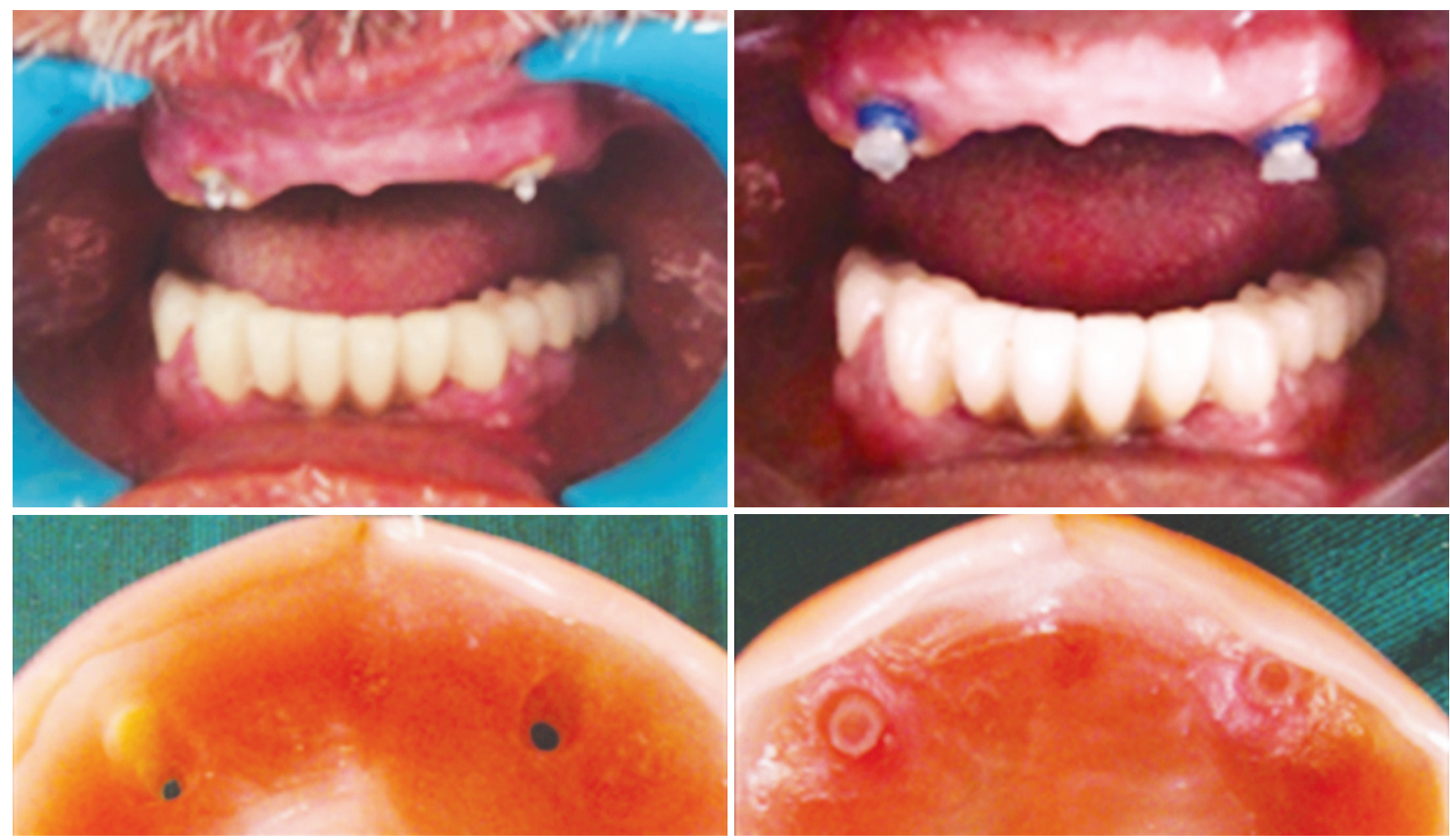

Fig. 10: Access post incorporation

of three different prosthesis and different techniques posed a challenge in achieving natural esthetic appearance, and in satisfying biomechanics and function. However, although technically challenging this approach facilitated a more conservative treatment in terms of using overdenture in the maxillary arch and achieving stability. Interdisciplinary approach to treatment planning and treatment sequencing, communication between all members of the disciplinary team, and a good understanding of the various biomechanics are the key to a successful result. Thus, a successful esthetics and functional result using three different types of prosthesis was achieved in the present full mouth rehabilitation.

\section{REFERENCES}

1. Ericsson I, Lekholm U, Branemark PI, Lindhe J, Glantz PO, Nyman S. A clinical evaluation of fixed-bridge restorations supported by combination of teeth and osseointegrated titanium implants. J Clin Periodontol 1986;13:307-312.

2. Van Steenberghe D. A retrospective multicentre evaluation of the survival rate of osseointegrated fixtures supporting fixed partial prosthesis in the treatment of partial edentulism. J Prosthet Dent 1989;61:217-223.
3. Binkley TK, Binkley CJ. A practical approach to full mouth rehabilitation. J Prosthet Dent 1987;57:261-266.

4. Battistuzzi PG, Van Slooten H, Kayser AF. Management of an anterior defect with a removable partial denture supported by implants: a case report. Int J Oral Maxillofac Implants 1992;7:112-115.

5. Goodacre CJ, Bernal G, Rungcharassaeng K, Kan JY. Clinical complications in fixed prosthodontics. J Prosthet Dent 2003;90: $31-41$.

6. Artzi Z, Nemcovsky CE, Dayan D. Nonceramic hydroxyapatite bone derivative in sinus augmentation procedures: clinical and histomorphometric observations in 10 consecutive cases. Int J Periodontics Restorative Dent 2003;23:381-389.

7. Wallace SS, Froum SJ. Effect of maxillary sinus augmentation on the survival of endosseous implant. A systematic review. Ann Periodontol 2003;8:328-343.

8. Mazor Z, Horowitz RA, Del Corso M, Prasad HS, Rohrer MD, Dohan Ehrenfest DM. Sinus floor augmentation with simultaneous implant placement using Choukroun's platelet rich fibrin as the sole grafting material: a radiologic and histologic study at 6 months. J Periodontol 2009 Dec;80(12):2056-2064.

9. Huynh, Rompre PH, Montplaisir JY, Manzini C, Okura K, Lavigne GJ. Comparison of various treatments for sleep bruxism using determinants of number needed to treat and effect size. Int J Prosthodont 2006;19:435-441. 